\title{
What Apparent Reasons Appear To Be
}

\begin{abstract}
Many meta-ethicists think that rationality only requires us to heed apparent normative reasons, not objective normative reasons. But what are apparent reasons? One hears two kinds of answers. On de dicto views, $p$ is an apparent reason for $\mathrm{S}$ to $\phi$ when it appears to $\mathrm{S}$ that $p$ is an objective reason to $\phi$. On de re views, $p$ is an apparent reason for $\mathrm{S}$ to $\phi$ when (i) $p$ 's truth would provide an objective reason to $\phi$ and (ii) it appears to $\mathrm{S}$ that $p$. De re views are currently more popular because they avoid overintellectualizing rationality. But they face problems owing to the way in which they do so. Some assume we can escape the problems by requiring more descriptive facts to be apparent or by appealing to defeat. But these strategies fail. So I defend a new view that is closer in spirit to de dicto views but less demanding (at least granting the assumptions needed to support overintellectualization worries). On this view, apparent reasons are apparent facts that agents are competently attracted to treating like objective reasons, where competence is indirectly defined in terms of objective reasons and a competence/performance distinction is drawn.
\end{abstract}

\section{Introduction}

Meta-ethicists often view normative reasons as objective facts that count in favor of actions and attitudes. These facts include ones to which we do not necessarily have privileged access. For example, the fact that the lemonade is arsenic-laced is a conclusive reason for you not to drink it. This fact remains a conclusive reason for you not to drink the lemonade even if you are in no position to see that the lemonade is arsenic-laced.

Clearly, however, you need not be irrational in drinking the lemonade if you are in no position to appreciate this fact. So, meta-ethicists like to separate rational $\phi$-ing from $\phi$-ing that is supported by all the objective normative reasons. Rationality retains an indirect connection to objective normative reasons: it requires responding to apparent objective reasons. On many views, the 'apparent' is not a success term. There may appear to be sufficient objective reasons to $\phi$ even if there are conclusive objective reasons not to $\phi$. The lemonade case illustrates this fact. Moreover, there may be no apparent reason to $\phi$ even if there is an objective reason to $\phi$. The same case illustrates this fact: while there is no apparent reason to refuse to drink the lemonade, there is an objective reason to refuse (viz., that the lemonade is lethal).

Now, many meta-ethicists who draw this distinction believe that rationality is just coherence. ${ }^{1}$ Accordingly, they assume that apparent reasons are apparent in a belief-relative sense. But we can understand 'apparent' more broadly without collapsing rationality into objective correctness. Epistemic rationality requires responding to the recommendations of

\footnotetext{
${ }^{1}$ See, for example, Scanlon (1998), Broome (1999, 2005, 2007, 2013), and Kolodny (2005).
} 
perceptual appearance even if this appearance is radically non-veridical (e.g., in the Matrix or other skeptical scenarios). It does not require responding to all the objective evidence out in the world. Many epistemologists who embrace these thoughts would not cash them out in coherentist terms (e.g., by treating perceptual appearances as beliefs).

As an epistemologist, I am predisposed to see the requirement to respond to apparent normative reasons as stronger than any coherence requirement. One could try to reduce this requirement to a coherence requirement. I independently find this project suspect, but what matters for our purposes is that even on non-coherentist views rationality is weaker than the kind of correctness that goes with doing what the totality of objective facts would favor. For not all objective facts are apparent, and not all apparent facts are real.

The focus of this paper is on what it takes for a consideration to be an apparent reason. I think the main ways in which meta-ethicists answer this question are flawed, and I will offer a new answer. In $\S 2$, I introduce two main types of view that meta-ethicists have endorsed: de dicto views and de re views. De re views are currently more popular because many worry that de dicto views overintellectualize rationality. While I agree about this worry, I think moving to standard de re views is a mistake. In $\S 3$, I pose some problems for de re views and show how potential responses fail. I then turn to my own view in $\S 4$, explaining how it avoids the problems for de re and de dicto views. Finally, I answer an objection to my view - and to all other views discussed earlier - in $\S 5$.

I will stress in advance that my real foe in this paper is the de re theorist. While I don't accept the de dicto view, I also don't reject it. Non-acceptance is weaker than rejection: I merely don't want to commit to the views in the philosophy of mind that the de dicto view would force us to accept on pain of overintellectualization. While many important features distinguish my view from the de dicto views in the literature, my view would entail a (new) version of the de dicto view if certain extreme views about concept possession that I reject were true. My view simply doesn't require these extreme views to succeed. So, while it is less demanding (granting the assumptions about concept possession that drive the overintellectualization worry), my view is closer in spirit to the de dicto tradition. I will explain these nuances further in the next section.

\section{Apparent Reasons De Dicto and De Re}

\subsection{De Dicto Views}

When meta-ethicists first began to distinguish between rationality and correctness, apparent reasons were understood very narrowly. For example, Scanlon (1998: 25) held that irrationality in its "clearest sense" occurs when someone "judges that something is a reason but fails to be affected by it in one of the relevant ways". Kolodny (2005) echoed him, 
holding that the core requirements of rationality are requirements to respond to our de dicto beliefs about normative reasons. These views are examples of a broader view:

DE DICTO: $\mathrm{R}$ is an apparent normative reason for $\mathrm{S}$ to $\phi$ iff it appears to $\mathrm{S}$ that $\mathrm{R}$ is an objective normative reason to $\phi$.

While Scanlon and Kolodny take the relevant sense of 'appears' to be belief-relative, it is not compulsory to do so. We have known at least since Chisholm (1957) that appearance words can be used in many ways. Besides the doxastic use, there are non-doxastic uses of 'appears'. Even if you fail to take any doxastic stance on whether P, it can still perceptually appear to you that P. Non-doxastic appearances are not confined to perceptual cases. Propositions in a priori domains can appear true in this way too: consider inconsistent triads of a priori plausible claims.

Normative propositions can appear true in this way too. So, if one agrees that rationality demands less than conformity with all the objective normative reasons but dislikes coherentism, one could preserve DE DICTO but understand the 'appears' less narrowly. One could agree that there is a more restricted kind of rationality that is belief-relative - viz., structural rather than substantive rationality. But one could deny that it is the only kind of rationality to be distinguished from fact-relative statuses like objective correctness. Substantivity and fact-relativity are orthogonal: apparent reasons are a clear illustration!

\subsection{Understanding the Overintellectualization Objection}

Even understood in this wider way, many meta-ethicists would reject DE DICTO. A major reason concerns overintellectualization. Parfit (2011: 118) expresses the concern well:

We can have rational beliefs and desires, and act rationally, without having any beliefs about reasons. Young children respond rationally to certain reasons or apparent reasons, though they do not yet have the concept of a reason. Dogs, cats, and some other animals respond to some kinds of reason...though they will never have the concept of a reason. And some rational adults seem to lack this concept....

Parfit's thoughts are plausible, carefully understood. ${ }^{2}$ But there are two unequally plausible ways to extract a challenge to DE DICTO. The most ambitious is a knock-down argument:

\footnotetext{
${ }^{2}$ Might it be insisted that while infants, toddlers and animals lack the concept of a normative reason, they have a related proto-concept? Isn't it plausible that even infants can believe that certain considerations count in favor? The concept of favoring may seem less sophisticated. But note that it is a relational concept: considerations count in favor of attitudes and acts. For us to explain the rationality of their beliefs, desires, etc., on the revised de dicto view, children must not only have the concept of favoring, but also the concepts of these attitudes. One cannot view the incomplete content $<\mathrm{R}$ counts in favor $>$ as the relevant object of children's thoughts and seemings. The content would have the form $<\mathrm{R}$ counts in favor of $\phi$-ing $>$, where $\phi$-ing could be believing, desiring, etc. Yet it is even more doubtful that infants and some toddlers have these mental state concepts. Many animals certainly lack them. So a problem remains.
} 


\section{The Strong Overintellectualization Argument}

1. Rational subjects must possess the concept of a normative reason if DE DICTO is true, since in order to host appearances with contents of the form $R$ is an objective normative reason to $\phi$ one must have this concept.

2. But rational subjects need not possess the concept of a normative reason.

3. So, DE DICTO is false.

While there is a version of the overintellectualization objection worth taking seriously, the Strong Overintellectualization Argument is not it. Defenders of DE DICTO could easily reject (1) or (2). Doing so just requires some burdensome commitments on which a general theory of apparent reasons and the nature of rationality would ideally be neutral.

For example, one might insist that possessing the concept of a normative reason is easier than Parfit and others suppose. One need not be able to articulate one's thoughts involving a concept to possess it, or be able to use the words that express the concept. But perhaps all that is clear is that infants, toddlers, and animals cannot articulate any beliefs about normative reasons. Perhaps, one might insist, they still have these beliefs.

Obviously, a burden remains: friends of DE DICTO must offer a positive story about how it is that children and animals possess the concept of a normative reason. Friends of DE DICTO might maintain that possessing the concept simply consists in having certain dispositions to treat considerations in ways that would be appropriate if they were real normative reasons. Proponents of the representational theory of mind (e.g., Fodor (1998)) will find this an implausible view about concept possession. Being in favor of the representational theory of mind myself, I would prefer a theory that does not force us to accept a purely dispositional account of concept possession.

One might take a different tack. One might deny that possessing the concept of a normative reason is necessary for hosting appearances with the content $R$ is a normative reason to $\phi$. For example, one might insist that one can host an appearance with the content $X$ is $F$ simply by being attracted to treat $\mathrm{X}$ like an $\mathrm{F}$. I would find this an unattractive hypothesis in the theory of content. Does it really seem to a dog that its owners are vending machines simply because this dog treats its owners like vending machines? On many views, this idea would be implausible if the content attribution is intended seriously - as it must, if the view is a de dicto view. I would prefer a view that doesn't raise these worries.

Friends of DE DICTO can surely defend their view to their own satisfaction by adopting burdensome views in the philosophy of mind or theory of content. But this highlights a different way to understand the objection. The objection is not that one can obviously be rational without having normative concepts. Instead, we can put it as follows: 


\section{The Modest Overintellectualization Argument}

1. A view about rationality that is defensible without invoking burdensome views in the philosophy of mind or theory of content is ceteris paribus preferable to a view that is indefensible on pain of overintellectualization if such views fail.

2. DE DICTO avoids overintellectualizing only if some burdensome views in the philosophy of mind or theory of content are true.

3. So, unless there is no defensible view of rationality that can avoid invoking these views, we should not endorse DE DICTO.

The conclusion does not tell us to deny DE DICTO. It just tells us to withhold belief and search for a view that does not make it compulsory to endorse burdensome views in the philosophy of mind or theory of content. The view I will offer in $\S 4$ is such a view. The conjunction of my view and these burdensome views view might entail DE DICTO. But the plausibility of my view does not depend upon the truth of these burdensome views.

A comparison vindicates the point. Consider the early literature on the Gettier problem. Clark (1963) thought that we could fix the justified true belief account of knowledge by suggesting that subjects who know that $\mathrm{P}$ do not essentially rely on inferences from falsehoods in arriving at their justified true beliefs that P. According to this picture, what is going awry in Gettier cases is that subjects are arriving at their justified true beliefs by essentially relying on inferences from falsehoods. The obvious worry about this proposal is that there are Gettier cases where subjects do not seem to perform inferences at all in arriving at their Gettiered beliefs (e.g., Fake Barn Country). One could try to attribute intricate subconscious inferences to these subjects, as Harman (1973) did. And if one did this, one could arguably explain all Gettier cases with a sophisticated Clarkean theory.

But today, virtually no one accepts this as a solution to the Gettier problem. This is not because everyone finds it obvious that subjects perform no relevant subconscious inferences in cases like Fake Barn Country. It is because an ideal solution to the Gettier problem would not require views in the philosophy of mind that few epistemologists would embrace. Hence the greater popularity in the later 1970s of defeasibility theories. These theories subsumed the good predictions of Clarkean theories without appealing to any controversial views in the philosophy of mind. The two kinds of theory would be extensionally equivalent if we accepted these controversial views. But defeasibility theories seemed preferable, since they did not require these controversial views to work.

The view that I will be developing in $\S 4$ stands to DE DICTO as defeasibility theories stand to theories in the Clarkean tradition. Again, my view would be extensionally equivalent to some version of DE DICTO if certain highly controversial views about concepts and content were true. But the plausibility of my view does not depend upon the truth of these views, and for this reason stands a better chance of survival. 
This is my main reason for not affirming DE DICTO. Again, I do not reject DE DICTO. But I will only affirm a theory that can get the right predictions without relying on any strong views in the philosophy of mind or theory of content. If I believed these strong views, I might embrace DE DICTO in my heart of hearts. But it is not a view that I want to assert: I want to assert something more modest, at least in certain respects.

\subsection{Other Concepts?}

Before setting aside de dicto views, it is worth considering a final response. I have only discussed de dicto views that invoke the concept of a normative reason. But there are other normative concepts that might not raise such stark overintellectualization worries. Besides the concept of a normative reason, there are thin evaluative concepts like goodness. There are also thick concepts, like gross, delightful, terrifying, and so on. Isn't it more plausible that even animals can conceputalize things in these ways?

Perhaps. I would still prefer a theory that did not require us to attribute any such concepts to all beings that can act and believe rationally. But the analogy with Clarkean responses to the Gettier problem is less obvious with these possibilities on the table.

So, why can't we just relax? Because the worries return when we look carefully. My worries concern the implications for epistemology. Suppose that Alpha is competent with some valid pattern of first-order inference - say, modus ponens. And suppose that it appears to Alpha that $\mathrm{P}$ and that Alpha knows that if $\mathrm{P}$ then $\mathrm{Q}$. This is a paradigm case of having an apparent reason to believe Q. How can a de dicto theorist explain this case? The theorist must suppose that it also appears to Alpha that believing $Q$ would be positively evaluable in some way. But must any subject in Alpha's position be capable of hosting an appearance with this content, in order to gain an apparent reason to believe Q?

Not plausibly. This proposal involves a new overintellectualization. This time, the overintellectualization has nothing to do with requiring the possession of certain normative concepts. The problem lies in requiring the possession of certain mental state concepts. The de dicto theorist must say that Alpha conceptualizes the doxastic response of believing $\mathrm{Q}$ in a positive light. But mental state concepts are sophisticated. Subjects do not need to be able to think about their own beliefs in order to perform rational first-order inferences as elementary as modus ponens.

One might again try to retreat to lax views about concept possession or otherwise argue that it is easier than it looks to think about one's mental states. But now the analogy with Clarkean theories is vivid. It is better to avoid making these strong claims in the philosophy of mind to save the de dicto theory. My view will have this advantage. 


\subsection{The $D e$ Re View}

But the view that I will offer is not the usual reaction to the overintellectualization objection. The usual reaction is to move from DE DICTO to a view of this form:

DE RE: $\mathrm{R}$ is an apparent reason for $\mathrm{S}$ to $\phi$ when (i) R's truth would give $\mathrm{S}$ an objective normative reason to $\phi$, and (ii) it appears to $\mathrm{S}$ that $\mathrm{R}^{3}$

This view is embraced by theorists like Parfit (2001, 2011), Schroeder (2007), and Way (2009). Like Scanlon and Kolodny, they often unpack 'appears' in a belief-relative manner. For example, Parfit (2011: 111) writes:

While reasons are given by facts, what we rationally want or do depends on our beliefs. If we have certain beliefs about the relevant, reason-giving facts, and what we believe would, if it were true, give us some reason, I am calling these beliefs whose truth would give us this reason. Such beliefs give us an apparent reason. When such beliefs are true, this apparent reason is also a real reason.... We ought rationally to respond to apparent reasons even if...these reasons are not real.

And Schroeder (2007: 14) says the following, where 'subjective reason' = 'apparent reason': "For $\mathrm{R}$ to be a subjective reason for $\mathrm{X}$ to do $\mathrm{A}$ is for $\mathrm{X}$ to believe $\mathrm{R}$, and for it to be the case that $\mathrm{R}$ is the kind of thing, if true, to be an objective reason for $\mathrm{X}$ to do A."

Once again, the belief-relative formulations are not mandatory. The 'appears' in DE $\mathrm{RE}$ could be understood in a non-doxastic sense of the sort mentioned earlier. Indeed, when it comes to stating his epistemological views, Schroeder abandons the belief-relative formulation and requires only that $\mathrm{R}$ be the content of some presentational mental state. ${ }^{4}$ Such states include things like perceptual experiences and intuitive seemings. If DE RE is to be taken seriously by epistemologists, it should be formulated in this less narrow way.

However formulated, DE RE avoids the overintellectualization of DE DICTO. It does not entail that rational subjects must possess any normative concepts, or that subjects must represent apparent reasons as reasons. So, given the Modest Overintellectualization Argument, it might seem that we should pursue DE RE.

\section{The Failure of $D e$ Re Views}

\subsection{The Problem of Unapparent Reasons}

But only if DE RE is plausible along other dimensions. It is not. Ironically, DE RE's flaws stem from the way in which it reacts to the overintellectualization of DE DICTO.

\footnotetext{
${ }^{3}$ This is formulated in a way that makes it sound like I am assuming that reasons are propositions. But this assumption is not essential to anything in this paper. It just makes certain formulations verbally simpler. If one prefers, one can rewrite everything in terms of states of affairs a la Dancy (2000). Indeed, I prefer the Dancyean picture. It would just lead to clunkier formulations in this context.

${ }^{4}$ See Schroeder (2011).
} 
Notice that DE RE does not merely suggest that rational subjects need not represent apparent reasons as objective reasons. If $\mathrm{DE} \mathrm{RE}$ is true, $\mathrm{R}$ can be an apparent reason for a subject to $\phi$ even if it would not be rational for her to treat $R$ like an objective reason to $\phi$. For even if it is not rational for a subject to treat $\mathrm{R}$ like an objective reason to $\phi$, it might remain apparent to her that $\mathrm{R}$ is the case, and $\mathrm{R}$ might still be a consideration that would be an objective reason to $\phi$ if it were the case. And this is that all DE RE requires for $\mathrm{R}$ to be an apparent reason to $\phi$ !

Worries about overintellectualization do not support this feature of DE RE. One can treat something like an $\mathrm{F}$ without representing it as an $\mathrm{F}$ or having the concept of an F. Some cat might treat its owners like vending machines without having the concept of a vending machine or representing its owners as vending machines. So the requirement that apparent reasons be considerations that it is rational to treat like good reasons is not overly intellectual. This requirement is plausible. How could we be rationally required to respond to considerations that it is not rational for us to treat like good reasons?

Yet DE RE implies that we could. This is a serious problem. I call it the Problem of Unapparent Reasons, since the problem is that DE RE classifies as apparent reasons considerations that are not apparent reasons.

Many possible cases fit this bill. Even if we know all the relevant descriptive facts, there might be objective reasons given by these facts that it would not be rational for us to treat like objective reasons. Our sensitivity to normative reality is limited. For those of us with normative concepts, this limitation can manifest in our inability to rationally settle certain normative questions. In such cases, (i) and (ii) in DE RE can easily be satisfied with respect to some consideration while the consideration fails to be an apparent reason.

The fundamental limitation clearly does not extend only to those of us who possess normative concepts. It might be true that any rational being has the ability to correctly respond to some would-be objective reasons. But this ability has bounds. Even given perfect descriptive knowledge, an ordinary rational being's competence only goes so far. It may not reach so far as to enable this being to rationally treat like objective reasons all the apparent facts that would be objective reasons if these facts were real. When the bounds of competence are surpassed, conditions (i) and (ii) in DE RE can easily be satisfied with respect to some consideration while the consideration fails to be an apparent reason.

One can construct simple counterexamples to DE RE without appreciating these deeper points. But I prefer putting the deeper points first, because they allow us to see how to forestall the main responses to simple counterexamples.

Let's consider these simple counterexamples. Here is one drawn from epistemology. Suppose it appears to Jones that $\mathrm{P}$-indeed, suppose Jones knows that P. And suppose that $\mathrm{P}$ logically entails Q. So $\mathrm{P}$ is an objective reason to believe Q. Both clauses of DE RE are satisfied: the relevant consideration is apparent, and this consideration would be an 
objective reason to believe $\mathrm{Q}$ if true (indeed, it is one). Compatibly with all this, Jones's inferential abilities might be too limited for him to be sensitive to the logical relation between $\mathrm{P}$ and $\mathrm{Q}$. Indeed, the entailment might be arcane, visible only to the greatest logicians. If so, Jones cannot rationally treat $\mathrm{P}$ like an objective reason to believe $\mathrm{Q}$. And if so, it is wrong to view Jones as having $\mathrm{P}$ as an apparent normative reason to believe $\mathrm{Q}$.

Notice that this differs from a standard objection to the view that believing that $\mathrm{P}$ is sufficient for possessing $\mathrm{P}$ as a normative reason. The standard objection to that view is that irrationally believing that $\mathrm{P}$ cannot put one in a better epistemic position with respect to P's consequences. ${ }^{5}$ But we stipulated that Jones knows that P. So the problem has nothing to do with his epistemic position with respect to $\mathrm{P}$. The problem lies in his inability to rationally treat $\mathrm{P}$ like an objective reason to believe $\mathrm{Q}$.

\subsubsection{Defeat?}

The problem is not plausibly addressed by an appeal to defeat. In the relevant sense of 'defeated', apparent reasons have to be defeated by other apparent reasons. In our case, the fact that explains why Jones cannot rationally treat $\mathrm{P}$ as a reason to believe $\mathrm{Q}$ is the fact that Jones's competence is limited. But this fact isn't one that itself must be apparent to Jones to prevent him from possessing $\mathrm{P}$ as an apparent reason to believe Q.

People can be deceived about their own abilities. They can regard themselves as geniuses when they are fools. If their incompetence is not apparent to them, it is not the sort of thing that could serve to defeat another apparent reason. Will they have other apparent defeaters owing to the mistakes their incompetence makes likely? Not necessarily. Some fools may arrive at mostly correct results by fluke. If so, they will not possess indirect evidence for believing themselves to be incompetent. So a defeat strategy will be inapplicable in some of these cases. Yet it is plausible that their incompetence prevents them from possessing apparent reasons of the sort that bear on substantive rationality.

Obviously, there is defeat in an objective sense in these cases. But that fact is irrelevant. In the sense of 'defeated' relevant to rationality, apparent reasons have to be defeated by other apparent reasons. Might our intuitions be confused, conflating objective and apparent defeat? Not plausibly. There can be unpossessed objective defeaters for perfectly rational beliefs. Many Gettier cases are like this, and our intuitions do not lead us astray in these cases. Intuitively, our case is nothing like these cases. It is plausible in our case that it is not rational for Jones to believe that $\mathrm{Q}$ on the basis of $\mathrm{P}$, but implausible that rationality is lacking in standard cases of unpossessed objective defeaters.

Let's put a nail in this coffin. Imagine again that $\mathrm{P}$ entails $\mathrm{Q}$, but that the entailment is an arcane one beyond Jones's competence. But now imagine that Jones treats $\mathrm{P}$ as a reason to believe $\mathrm{Q}$ by means of an overgeneralizing incompetence that has, by sheer

\footnotetext{
${ }^{5}$ Schroeder (2011) addresses that standard objection, but not the one at issue here.
} 
luck, yielded correct results so far. Imagine that he lacks the second-order competence to appreciate his first-order incompetence. According to DE RE, he has an apparent reason to believe Q. By stipulation, he also has no apparent defeaters. Now suppose Jones believes $\mathrm{Q}$, and that $\mathrm{Q}$ is true. By the lights of $\mathrm{DE} \mathrm{RE}$, Jones has a rational true belief that $\mathrm{Q}$. Clearly, Jones does not know Q. DE RE thus suggests that this case is a kind of Gettier case - a case of rational true belief without knowledge. This is absurd. This case is nothing like a Gettier case. The obvious reason is that Jones's belief in Q is not rational.

Finally, notice that the basic intuition in the first case is that Jones cannot rationally treat $\mathrm{P}$ like an objective reason to believe $\mathrm{Q}$, from which we infer that $\mathrm{P}$ is not an apparent reason for him to believe $\mathrm{Q}$. So we are not committing the fallacy of assuming that there is no reason when there is a weak one. ${ }^{6}$ We are not assuming this but concluding it.

These matters of degree can be made explicit. Given Jones's limited abilities, it is not rational to any degree for him to treat $\mathrm{P}$ like an objective reason to believe Q. Might he have an apparent reason to believe $\mathrm{Q}$ of zero weight? This differs from our conclusion only verbally. A reason with no weight is not a normative reason.

\subsubsection{Why Not Demand the Enablers To Be Apparent?}

The friend of DE RE could instead try to revise the view by requiring more descriptive information to be apparent to the subject. But while this strategy can help to address some cases, it cannot solve the fundamental problem.

To bring this out, let us consider the main version of this strategy. Notice that in the case involving Jones, P's truth would be an objective reason to believe Q because P logically entails Q. Facts about what is a reason for what are not brute facts. P will generally be a reason for some attitude toward Q because further descriptive facts obtain. This is not to say that these extra descriptive facts are further reasons to have the attitude toward Q. They are enabling conditions. ${ }^{7}$ So one might revise DE RE thus:

ENABLED DE RE: $\mathrm{R}$ is an apparent reason for $\mathrm{S}$ to $\phi$ iff (i) R's truth would be an objective normative reason to $\phi$ given enabling conditions $\mathrm{C}$, (ii) it appears to $\mathrm{S}$ that $\mathrm{R}$, and (iii) it appears to $\mathrm{S}$ that $\mathrm{C}$.

But this view also fails: it is both too strong and too weak.

The view is clearly too strong for perceptually apparent epistemic reasons. Either intrinsic or relational features of perceptual experiences enable them to provide reasons for belief. Intrinsic features might include the presentational character of perceptual experience; relational features might include the reliable links between experience and reality.

\footnotetext{
${ }^{6}$ Schroeder $(2007, \mathrm{Ms})$ calls this the 'negative existential reasons fallacy'. I agree that it is a fallacy. I just do not see that this fallacy is driving the present argument. I also do not see how Schroeder's usual strategy for explaining away the negative existential reasons intuition works here.

${ }^{7}$ Cf. Dancy (2004).
} 
We do not need to represent these enabling conditions to form rational perceptual beliefs. This would be a serious overintellectualization of the very sort that DE RE was designed to avoid. Children and animals do not form beliefs about these features of perceptual experience. Even adults with the relevant concepts need not do so.

ENABLED DE RE is too strong even for apparent deductive reasons. Having beliefs about entailments is one way to be sensitive to logical relations between propositions. But it is not the only way. Another way is to have the ability to competently infer one proposition from another by following an inference rule. Instead of reasoning

(i) $\neg(\mathrm{P} \vee \mathrm{Q})$

(ii) If $\neg(\mathrm{P} \vee \mathrm{Q})$, then $\neg \mathrm{P} \wedge \neg \mathrm{Q}$

(iii) So, by modus ponens, $\neg \mathrm{P} \wedge \neg \mathrm{Q}$,

one could directly infer (iii) from (i) by relying on one of the DeMorgan rules.

We cannot replace all rules by extra premises. Even axiomatic systems need some rules. And most people simply do not reason axiomatically. People often use rules rather than conditionals that express logical truths plus modus ponens. Admittedly, most people are not so logically competent that they can use any potential rules as easily as they use modus ponens. But equally clearly, there is a spectrum of acumen. Some people do have the native logical abilities to cleave reliably to far more intricate patterns.

If we accept ENABLED DE RE, we could not describe all the apparent reasons these people can acquire. Competent inferrers need not represent the patterns to which they cleave to possess premises as apparent reasons for conclusions. Yet ENABLED DE RE entails that the premises fail to be apparent reasons for these subjects' conclusion beliefs.

So, it cannot be claimed that what Jones is missing must be a further conditional belief. Such a belief could help. But that is not the only way his situation could improve. Rather than gaining a new conditional belief, Jones could acquire a new ability. DE RE and ENABLED DE RE fail to accommodate this possibility. This is a problem. These theories all represent a subject's set of apparent reasons by a set of descriptive considerations that are apparent to the subject. ENABLED DE RE differs from DE RE only in requiring more descriptive considerations to be apparent. This strategy is clearly misguided.

While too strong in one respect, ENABLED DE RE is too weak in another. What fundamentally matters is not how much descriptive knowledge an agent possesses. Agents might have equal descriptive knowledge, yet more considerations might be apparent reasons for one than for another. Among subjects with normative concepts, the difference can manifest in one's having greater normative knowledge. Among subjects without normative concepts, the difference can manifest in one's being in a position to rationally treat more considerations like objective reasons. And that may owe to a difference in competence. 
As we trace beings down the spectrum of competence, fewer considerations will be apparent reasons for them. But what diminishes down the spectrum is not necessarily the number of apparent descriptive facts. We can imagine beings who grasp as many descriptive facts as us but for whom fewer reasons are apparent owing to their lesser abilities. ENABLED DE RE cannot capture these cases. It predicts that the range of apparent reasons for a subject is simply a function of the number of apparent descriptive facts for that subject. By neglecting the role of competence, it makes many bad predictions.

\subsubsection{Morals}

I think the proper response to these observations is to abandon the approach represented by standard de re theories, and to find a theory that explicitly captures the role of competence. This should not involve a retreat to DE DICTO. Given some controversial views in the philosophy of mind, this better theory might entail DE DICTO. But there is no obligation to commit to these views. We can choose a strictly weaker theory.

Might defenders of DE RE have another way to capture the role of competence? Perhaps they could try to weaken the link between apparent reasons and rationality. They might claim that it is rational for $\mathrm{S}$ to $\phi$ iff (i) there are sufficient apparent reasons for $\mathrm{S}$ to $\phi$ and (ii) $\mathrm{S}$ is in a position to competently treat them like objective reasons to $\phi$.

But this would be unsatisfying. Does someone with little mathematical ability have apparent reasons to believe the most abstruse theorems of mathematics simply in virtue of knowing the axioms? Not plausibly: owing to this person's limited abilities, he cannot rationally treat these axioms like reasons to believe the theorems. It is better to place the competence constraint directly on the having of apparent normative reasons to $\phi$.

\subsection{The Problem of Wouldn't-Be Reasons}

So far the objection has been that the conditions in de re theories are insufficient for a consideration to be an apparent reason. Are these conditions even necessary?

While its importance can be overstated, condition (ii) is necessary: $\mathrm{R}$ cannot be an apparent reason for $\mathrm{S}$ to $\phi$ if it is not apparent to $\mathrm{S}$ that $\mathrm{R}$. But we should doubt condition (i), which entails:

$\left(i^{*}\right) \mathrm{R}$ is an apparent normative reason for $\mathrm{S}$ to $\phi$ only if R's truth would give $\mathrm{S}$ an objective normative reason to $\phi$.

$\left(i^{*}\right)$ is stronger than it might seem. Notice, for example, that it entails:

$\left(i^{* *}\right)$ If $\mathrm{R}$ is true, $\mathrm{R}$ is an apparent normative reason for $\mathrm{S}$ to $\phi$ only if $\mathrm{R}$ is an objective normative reason for $\mathrm{S}$ to $\phi$. 
To see this, suppose that $\mathrm{R}$ is true. ( $\mathrm{i}^{*}$ ) entails that $\mathrm{R}$ is an apparent reason to $\phi$ only if its truth would be an objective reason to $\phi$. Since $\mathrm{R}$ is true, it follows that R is an objective reason to $\phi$. So, $\left(i^{*}\right)$ entails that true apparent reasons to $\phi$ are objective reasons to $\phi$.

But we should reject this claim. Suppose that it appears to some scientists that it is a law of nature that Fs are Gs, but this appearance is misleading. Every time an F appeared to be a G involved an illusion; in reality, Fs are nomically guaranteed not to be Gs. Now suppose that the scientists have been correctly told that $\mathrm{X}$ is an $\mathrm{F}$, but nothing more. The fact that $\mathrm{X}$ is an $\mathrm{F}$ is an apparent reason for the scientists to believe that $\mathrm{X}$ is a $\mathrm{G}$. But the fact that $\mathrm{X}$ is an $\mathrm{F}$ is not an objectively good reason to believe that $\mathrm{X}$ is a $\mathrm{G}$. Objectively speaking, the fact that $\mathrm{X}$ is an $\mathrm{F}$ is a conclusive reason to believe that $\mathrm{X}$ is not a $\mathrm{G}$.

There is a more general problem. We can state it as an argument against DE RE:

\section{The Argument From Wouldn't-Be Reasons}

1. It is possible to rationally treat a consideration $\mathrm{R}$ like an objective reason to $\phi$ even if $\mathrm{R}$ would not in fact be an objective reason to $\phi$ if true.

2. If it is rational for one to treat $\mathrm{R}$ like an objective reason to $\phi, \mathrm{R}$ is an apparent reason for one to $\phi$.

3. So, it is possible for there to be apparent reasons for one to $\phi$ that wouldn't in fact be objective reasons for one to $\phi$ if true.

4. If (3), DE RE is false (because condition (i) is false).

5. So, DE RE is false (because condition (i) is false).

Cases like the two just mentioned support premise (1). Premise (2) seems like a truism. The rest of the argument is straightforward. This is a serious problem for DE RE, which we might call the Problem of Wouldn't-Be Reasons.

This problem undermines DE RE's central explanatory resource. It is obvious that not just any apparent fact is an apparent reason to $\phi$. So, we ask, what makes an apparent fact into an apparent reason to $\phi$ ? If a theory of apparent reasons cannot answer this question, it is defective. But the only answer that de re theorists give is that this apparent fact must be one which would be an objective reason to $\phi$ if it were real. The Argument from Wouldn't-Be Reasons suggests that this answer cannot answer our central question.

How can a de re theorist respond? The only options are to (A) question premise (2)'s status as a truism, or (B) deny that cases like the case of the misled scientists support (1).

Against Strategy (A). Consider strategy (A) first. One might complain that all that is clear in the case of the misled scientists is that they would be rational to believe that $\mathrm{X}$ is a $\mathrm{G}$. One might claim that this belief would be rational not because the fact that $\mathrm{X}$ is $\mathrm{F}$ is an apparent reason for them to believe that $\mathrm{X}$ is a $\mathrm{G}$. It would be rational simply 
because it is rational for them to treat X's being $\mathrm{F}$ like an objective reason to believe $\mathrm{X}$ is a G. And that treatment would be rational on de re grounds: so far every F has appeared to be $\mathrm{G}$.

I doubt that this saves DE RE. DE RE still implies that the fact that $X$ is $F$ is not an apparent reason for the scientists to believe that $\mathrm{X}$ is a $\mathrm{G}$. This is itself an intolerable implication. So the starting point is flawed: it simply isn't true that all that is clear in the case of the misled scientists is that it would be rational for them to believe that $\mathrm{X}$ is a $\mathrm{G}$.

Still, the second part of strategy (A) needs to be addressed-i.e., the suggestion that it is rational for the scientists to treat X's being $\mathrm{F}$ like an objective reason to believe that $\mathrm{X}$ is a $\mathrm{G}$ on purely de re grounds. For this suggestion contradicts a broader moral I drew.

It is can sound plausible that there are de re reasons why it is rational for the scientists to treat X's being $\mathrm{F}$ like an objective reason to believe $\mathrm{X}$ is a G. Isn't the fact that all Fs have appeared to be Gs an apparent reason to treat X's being F like an objective reason to believe that $\mathrm{X}$ is a $\mathrm{G}$ ? If so, the explanation of rational treating at least remains de re.

My worry about this response is that it trades on tacitly assuming the presence of something beyond mere de re appearance - viz., competence. The crucial question is whether any beings to whom (a) all Fs have appeared to be Gs would be (b) at least prima facie rational to treat the apparent fact that $\mathrm{X}$ is $\mathrm{F}$ like an objective reason to believe that $\mathrm{X}$ is a G, where (b) is explained wholly by (a). The answer to this question is 'no'. There are surely possible beings who lack the competence to project inductively from past experience. For such beings, all Fs could appear to be Gs, and yet it could fail to be even prima facie rational for these beings to treat the fact that a new $\mathrm{X}$ is $\mathrm{F}$ like an objective reason to believe that $\mathrm{X}$ is a $\mathrm{G}$. The explanation is that they lack a kind of competence.

This echoes an earlier point. Any adequate theory of apparent reasons must honor the role of competence. Apppealing to de re appearances of objective reasons cannot alone secure this desideratum. Hence, the deeper moral from the Problem of Wouldn't-Be Reasons stands.

Against Strategy (B). Strategy (A) fails. What about strategy (B), which involves denying that the case of the misled scientists supports premise (1)? This strategy is even less plausible. There are only two ways to pursue it. One way is to deny that it is rational for the scientists to treat the fact that $\mathrm{X}$ is $\mathrm{F}$ like an objective reason to believe that $\mathrm{X}$ is a G. This is clearly wrong. Another way would be to hold that the fact that $\mathrm{X}$ is $\mathrm{F}$ is, after all, an objective reason to believe that $\mathrm{X}$ is a G. But this is false by stipulation!

One might try to dispute the stipulation. But once we get clear on what it does not exclude, there is no clear reason to do so. We did not stipulate that there is no other objective reason for the scientists to believe that $\mathrm{X}$ is a $\mathrm{G}$. The claim was that the fact that $\mathrm{X}$ is an $\mathrm{F}$ is not an objective reason to believe that $\mathrm{X}$ is $\mathrm{G}$. This is the only claim that 
needs to be made. It entails that an apparent fact can be an apparent reason even if this apparent fact would not be an objective reason if it were real. We could still agree that the fact that all Fs have appeared to be Gs is a non-trivial objective reason to believe that $\mathrm{X}$ is a $\mathrm{G}$. But this does not undermine my point, which concerned the fact that $\mathrm{X}$ is an $\mathrm{F} .{ }^{8}$

There is no good solution, then, to the Problem of Wouldn't-Be Reasons. Given this problem and the Problem of Unapparent Reasons, I doubt any pure de re theory will do.

\section{Competence, Appearance, and Treating}

\subsection{A Key Ingredient: Treating}

A better theory is worth seeking. An ideal theory would avoid the problems for de re theories without regressing to the excesses of de dicto theories.

How can one walk this fine line? Well, remember that it is possible to treat a consideration like an objective reason without having any normative concepts or beliefs. A natural thought is to invoke this less demanding idea in a new theory. We could construct a theory that is structurally like DE DICTO, but replace beliefs about objective reasons with competent attractions to treat considerations like objective reasons.

The Problem of Unapparent Reasons recommends this approach. The problem arose because it is possible for a proposition whose truth would provide an objective reason to appear true without one's being in a position to rationally treat its apparent truth like an objective reason. It makes sense to construct a theory that honors this thought. It would, however, be hasty to construct a theory just on the basis of this thought. The following theory will not do:

RATIONALLY ATTRACTED TO TREAT (RAT): $\mathrm{R}$ is an apparent normative reason for $\mathrm{S}$ to $\phi$ iff (i) it appears to $\mathrm{S}$ that $\mathrm{R}$, and (ii) $\mathrm{S}$ is rationally attracted to treating $\mathrm{R}$ like an objective normative reason to $\phi .{ }^{9}$

As a necessary biconditional, RAT is plausible. But as a substantive theory, it is unsatisfying. Like other theorists, I want to explain rationality in terms of apparent reasons. RAT looks circular from this perspective.

Still, RAT is extensionally plausible. So it would be nice to find an extensionally equivalent theory that does not appeal to rationality.

\subsection{Another Key Ingredient: Competence}

To see what such a theory would look like, remember another the role of competence. If Jones's logical competence is limited, then even if it is apparent to Jones that $\mathrm{P}$ and $\mathrm{P}$

\footnotetext{
${ }^{8}$ This forestalls application of the strategy from Lord (2010).

${ }^{9}$ Here and elsewhere, being attracted to treat $X$ like an $F=$ feeling the pull to treat $X$ like an $F$.
} 
logically entails $\mathrm{Q}$, it will not follow that $\mathrm{P}$ is an apparent reason for him to believe Q. As I have stressed, what is at bottom needed to gain apparent reasons is greater competence, not just further descriptive beliefs or appearances.

How is competence here to be understood? If objective reasons are the basic normative items - as I've assumed with Parfit, Scanlon, et al.-competence here must be analyzed in terms of objective reasons and non-normative items. I think the competence to invoke is a competence

to treat considerations like objective reasons of some relevant kind only if

these considerations would, if true, be objective reasons of this kind

Call dispositions with this structure objective reasons-sensitive competences. Such competences need not be infallible. Something might have a disposition to $\phi$ even if it does not always $\phi$. This does not mean that the disposition is a disposition to do something weaker than $\psi$-ing. It just means that it is a less than infallible disposition to $\psi$.

To see why such competences matter, consider again the beings that lack the competence to inductively generalize from experience. Even if P's truth would inductively support believing $\mathrm{Q}$ and it is apparent to one of these beings that $\mathrm{P}$, this being does not ipso facto have an apparent inductive reason to believe $\mathrm{Q}$. To gain $\mathrm{P}$ as an apparent inductive reason to believe $\mathrm{Q}$, what else does this being need? What this being needs is a disposition

to treat considerations like objective inductive reasons for belief only if

these considerations would, if true, be objective inductive reasons for belief

Together with the appearance that $\mathrm{P}$, is this competence all that one needs to gain $\mathrm{P}$ as an apparent inductive reason to believe Q?

Not quite. To see this, consider Julia. Julia is highly inductively competent. Right now, the appearance that $\mathrm{R}$ is attracting Julia to inductively infer that $\mathrm{S}$. But on this rare occasion, Julia's attraction does not manifest her inductive competence. While Julia is biased only with respect to a single topic, $\mathrm{R}$ and $\mathrm{S}$ concern this topic. We can even suppose that Julia's bias by sheer luck gets it right here: totally unbeknownst to Julia, $\mathrm{R}$ does greatly raise the objective probability that $\mathrm{S}$. Still, the mere fact that Julia (a) is attracted to inductively infer $\mathrm{S}$ on the basis of the apparent fact that $\mathrm{R}$ and (b) possesses inductive competence doesn't (c) convert $\mathrm{R}$ into an apparent normative reason for Julia to believe S. What is needed for (c) is for Julia's attraction to manifest her competence.

We can generalize from this point and earlier points to get a better theory: 
COMPETENTLY ATTRACTED TO TREAT (CAT): $\mathrm{R}$ is an apparent reason for $\mathrm{S}$ to $\phi$ iff (i) it appears to $\mathrm{S}$ that $\mathrm{R}$, (ii) $\mathrm{S}$ is attracted to treating $\mathrm{R}$ like an objective reason to $\phi$, and (iii) this attraction manifests $\mathrm{S}$ 's relevant reasons-sensitive competence,

- where a relevant reasons-sensitive competence is a competence to treat R-like considerations like objective reasons to do $\phi$-like things only if they are objective reasons to do $\phi$-like things. ${ }^{10}$

CAT is attractive. It avoids the Problem of Unapparent Reasons with its appeal to treating and competence, and hence captures the main advantage that DE DICTO has over DE RE. But it does so without any overintellectualizations.

\subsection{CAT and the Problem of Wouldn't-Be Reasons}

It is worth pausing, however, to explain why CAT also does not invite the Problem of Wouldn't-Be Reasons. There are two reasons why it does not.

Reason 1: The Fallibility of Competence. First, CAT does not assume that competences are infallible. One might be competently attracted to treat some consideration like an objective reason to $\phi$ even if the truth of this consideration would not be an objective reason to $\phi$. This does not mean that the competence is a competence to do something weaker than $\phi$-ing. It is just a less than fallible competence to $\phi$.

Reason 2: The Competence/Performance Distinction. Secondly and more importantly, there is a deeper competence/performance distinction. ${ }^{11}$ Having the competence to succeed does not entail being in a position to reliably succeed if one tries. A competence is a disposition to succeed. Just like other dispositions, there are favorable and unfavorable conditions for its successful manifestation.

Unfavorable conditions do not destroy competence. An archer retains the competence to hit the bull's-eye even when surprise gusts prevent her from being in a position to do so. An agent with the same competence could be relocated to a systematically unfavorable environment and be hoodwinked about its favorableness by a trickster. Consider a color expert who is systematically tricked by unusual lighting induced by a trickster. Her expertise is not destroyed, though she will be unreliable. The expertise may even be displayed in a sense weaker than proper manifestation. Compare how a car can exhibit its virtues for the road even in a display room.

All these points apply to objective reasons-sensitive competences. We find an initial illustration in the case from Williams (1981) where Bernie gets duped in his favorite bar,

\footnotetext{
${ }^{10}$ I use 'do' in a broad sense here to refer to attitudes as well as actions.

${ }^{11}$ In what follows, I am indebted to Ernest Sosa - in particular, to Sosa (2010)'s illuminating discussion of competence, and Sosa $(1991,1993)$ 's influential take on the new evil demon problem for externalist accounts of justification. What I will say simply generalizes what Sosa has already said in epistemology.
} 
receiving a glass of petrol and tonic that is visually indiscriminable from the gin and tonic that he typically orders. Bernie's prudence is not undermined by the fact that he is about to drink some petrol. Indeed, assuming that Bernie would benefit from the drink that he requested, his prudence is displayed, though not strictly manifested. Conditions are simply unfavorable: through no fault of his own, he does something bad for him.

It is easy to imagine an agent who systematically lands in unlucky circumstances through no fault of her own. Like other dispositions to succeed, reasons-sensitive competences may not even guarantee actual reliability. One could competently treat a vast range of apparent considerations like objective reasons even if they wouldn't be objective reasons if true. All we need is for the circumstances to be both unfavorable and misleading.

Appreciating these divergences between competence and reliability simpliciter lets us avoid the Problem of Wouldn't-Be Reasons. We see that it possible for one to competently treat many considerations like objective reasons even if they would not be objective reasons if true. This is why many apparent reasons need not be objective reasons if true.

Although CAT nicely avoids the Problem of Wouldn't-Be Reasons, it does establish a stronger connection between rationality and objective reasons than many have assumed. While it correctly denies that all apparent reasons are would-be objective reasons, it does entail a weaker conditional-viz., that:

if conditions for the exercise of competence are favorable, then considerations that are competently treated like objective reasons are likely to be objective reasons

Since competences are not infallible even in favorable circumstances, it does not follow that any consideration that is competently treated like an objective reason is an objective reason. But it is likely to be, in an objective sense: in favorable conditions, the competence has a propensity to yield treatings that are correct.

There would be a problem if it were possible for (i) a consideration $\mathrm{R}$ to satisfy the conditions in CAT while (ii) it is not rational for the subject to treat $\mathrm{R}$ like an objective reason. But there is no compelling reason to believe this is possible. In every case in which it is not rational to treat $\mathrm{R}$ like an objective reason, it will be implausible that one's treating it like an objective reason can display the relevant competence. Consider an archer who is rationally misled into thinking there will be gusts that require shooting at a bizarre angle. If the archer did not shoot at this angle given this evidence, it would be implausible to think that she would display her competence. Still, there are conclusive objective reasons for her not to take the angle shot. After all, there will not be gusts!

I say the stronger connection with objective reasons that CAT establishes is a virtue. While rationality does not guarantee reliability, the capacities that rational subjects exercise in bad cases are the same capacities that actually reliable people exercise. The differences lie in the favorableness of the circumstances and our sensitivity to them. While 
we must recognize a notion of rationality that falls in between coherence and correctness, rationality is not intelligible independently of correctness. It is a competence to achieve correctness, however fallible and unhelpful in unfavorable circumstances.

\subsection{Further Analysis of Key Ingredients}

CAT is the best theory we've seen. It steals the virtues of DE RE and DE DICTO while avoiding their vices. But crucial concepts of the theory deserve further elucidation.

\subsubsection{More on Treating and Attraction}

Consider treating again. It is, I have stressed, intuitive that we can treat considerations like objective reasons without having any normative concepts. Still, what exactly is it to treat $\mathrm{P}$ like an objective normative reason to $\phi$ ?

To treat $\mathrm{P}$ like an objective normative reason to $\phi$ is to be disposed to respond to the appearance that $\mathrm{P}$ in all or at least most of the ways that would be favored if $\mathrm{P}$ were an objective normative reason to $\phi$. Why 'all/most' rather than 'some'? My reason for imposing this stronger requirement is to get the right results in cases of supposition and pretense. We do not want the relevant kind of treating to be compatible with pretense.

If you pretend for the sake of argument that $\mathrm{P}$ is a conclusive objective reason to $\phi$, you are not irrational if you fail to $\phi$ given the appearance that P. But if you competently treat $\mathrm{P}$ like a conclusive objective reason to $\phi$ in the sense relevant to rationality, you are irrational if you fail to $\phi$ given the appearance that $\mathrm{P}$. The fundamental difference is straightforward. If you merely pretend or suppose for the sake of argument that $\mathrm{P}$ is a conclusive objective reason to $\phi$, there will be many ways that you are not disposed to respond to the appearance that $\mathrm{P}$ which would be correct $\mathrm{P}$ if $\mathrm{P}$ were a conclusive objective reason to $\phi$. You will not, for example, be disposed to adopt the stable attitudes that would be appropriate if $\mathrm{P}$ were a conclusive objective reason to $\phi$.

If this is what treating involves, why does CAT say only that apparent reasons are considerations that one is attracted to treating like objective reasons? Why not require that apparent reasons be considerations that one actually treats like objective reasons?

Here is the main reason for requiring less. Plausibly, weak-willed agents can have conclusive apparent reasons to $\phi$ and yet fail to be motivated to $\phi$. If CAT required actual treating, it would imply that such agents are impossible. Since this kind of agent seems possible, we want to require less. Nevertheless, when one is weak-willed in the face of an apparent reason, one is not left entirely cold. Real akratic agents will at least feel some pull to treat the apparent reason like an objective reason, if it really is an apparent reason for them. The trouble with the akratic agent is that her feeling this pull is not sufficient to make her treat the relevant consideration like an objective reason to $\phi$. 
So the weaker requirement is apt. Why does CAT require even this much? Couldn't there be a sociopath who has conclusive apparent reasons to $\phi$ but who is left entirely cold, failing even to feel the pull to treat these considerations as normative reasons to $\phi$ ?

I find it implausible that this particular kind of sociopath is possible. Obviously, there are conclusive objective reasons for these sociopaths not to act as they do. But we are talking about apparent normative reasons. I don't see how a consideration could be an apparent normative reason for someone to $\phi$ if the apparent truth of this consideration doesn't even make her attracted to treat her situation like one in which there is an objective reason to $\phi .{ }^{12}$ It seems better to describe sociopaths as lacking the ability to acquire certain objective reasons as apparent reasons - just as CAT implies.

"But can't it be apparent to sociopaths that what they are doing is morally wrong?" Of course. But CAT doesn't imply otherwise. What it implies is that the appearance that something is morally wrong fails to give the sociopath an apparent normative reason. What is apparently immoral needn't be equally apparently disfavored by objective reasons. Morality may seem to the sociopath just like etiquette seems to the enlightened. Indeed, even in the more substantive sense of 'rational' that falls in between coherence and correctness, it sounds clearly false to deem sociopaths irrational. ${ }^{13}$ Yet this kind of rationality consists in correctly responding to apparent normative reasons. What sociopaths lack are, precisely, conclusive apparent normative reasons not to do what they do. CAT's predictions here are plausible.

\subsubsection{More on Competence}

Another crucial notion in CAT that deserves further comment is the notion of competence. Earlier I said that the competence needed is a competence to:

to treat considerations like objective reasons of some relevant kind only if

these considerations would, if true, be objective reasons of this kind

I have already talked at length about why requiring objective reasons-sensitive competences in a theory of apparent reasons does not lead to a version of the Problem of Wouldn't-Be Reasons. Still, questions remain about these competences.

A central question concerns their individuation. It is clear that to have an apparent deductive reason to believe $Q$, it is not necessary that a subject be competent with every

\footnotetext{
${ }^{12}$ Once again, 'is attracted to $\phi$ ' just means 'feels the pull to $\phi$ '. It can sound odd to use talk of attraction in the context of sociopaths and morality. But given what the language means, this is no objection.

${ }^{13}$ Cf. Williams (1981).
} 
kind of deductive inference. But if 'reasons of the relevant kind' is understood in a coarsegrained way, CAT might seem to make this crazy demand: the relevant kind of reason might then just be deductive reason for belief.

Accordingly, we should want a more fine-grained picture. But we don't want too much fineness of grain. Consider the disposition to:

(a) treat the apparent conjunctive fact that Bob is 6 feet tall and Mary is 5 feet tall like an objective reason to believe that Bob is taller than Mary

This disposition is a competence: the reality of the apparent fact in question would be an objective reason to believe that Bob is taller than Mary. But we can imagine possible people who have this disposition but lack related dispositions, such as the disposition to:

(b) treat the apparent conjunctive fact that Sally is 5 feet tall and Billy is 4 feet tall like an objective reason to believe that Sally is taller than Billy

Consider, indeed, a subject who has no further dispositions of this form. Call him Weirdo. The only disposition Weirdo has is (a). Weirdo has the reverse of disposition (b): he will treat the apparent conjunctive fact mentioned in (b) like an objective reason to disbelieve that Sally is taller than Billy. Weirdo fails to manifest any grip on why the apparent conjunctive fact in (a) would be an objective reason to believe that Bob is taller than Mary.

We do not want to respond to this observation by requiring that a subject must have beliefs about why a consideration would be an objective reason in order to possess it as an apparent reason. This would be a gross overintellectualization. We can have competences to respond to certain sorts of reasons without having detailed knowledge of what makes them good reasons. So, what we want to require is that a subject have competence beyond the trivially narrow competence to treat one highly specific reason like an objective reason.

How should we require more? Note that there is a broader inferential pattern to which Weirdo fails to be sensitive:

(A) $\mathrm{X}$ is $m$ units tall.

(B) $\mathrm{Y}$ is $n>m$ units tall

(C) $\mathrm{Y}$ is taller than $\mathrm{X}$.

Of course, not all objective epistemic reasons qualify as such in virtue of being subsumed under necessarily truth-preserving inference patterns. But even ampliative epistemic reasons and non-epistemic reasons sometimes fit into patterns. The fact that all observed ravens are black is an objective reason to believe that all ravens are black precisely because facts of the form all observed Fs are Gs are generally objective reasons to believe conclusions of the form all Fs are Gs. The fact that it is healthy to eat vegetables is an objective 
reason to intend to eat them precisely because facts of the form it is healthy to eat $X$ are generally objective reasons to form intentions with contents of the form I eat $X$.

When reasons to fall into patterns, we can better understand the competences invoked by CAT. When there is a good pattern of reasoning that subsumes the subject's reasoning, the competences will be competences to treat considerations like objective reasons in accordance with some relevant pattern. ${ }^{14}$ Not all such reasoning must be inferential. Suppose that I see that there is a red sphere before me. If I form the belief that there is a red sphere before me in response to this visual experience, I believe for a reason. But this instance of believing for a reason is not inferential. Clearly, though, there is a general pattern of good reasoning that my transition instantiates: namely, treating the fact that I have an experience with a certain content like an objective reason to believe that content.

So CAT can be modified:

$\left(\mathrm{CAT}^{*}\right) \mathrm{R}$ is an apparent reason for $\mathrm{S}$ to $\phi$ iff

(i) it appears to $\mathrm{S}$ that $\mathrm{R}$,

(ii) $\mathrm{S}$ is attracted to treating $\mathrm{R}$ like an objective reason to $\phi$,

(iii) this attraction manifests S's competence to treat considerations like objective reasons to do $\phi$-like things only if they are objective reasons to do $\phi$-like things,

and

(iv) if there are patterns of good reasoning that subsume the favoring relation between $\mathrm{R}$ and $\phi$-ing, $\mathrm{S}$ is competent with some and manifests this competence.

$\mathrm{CAT}^{*}$ only requires that the subject be competent with some general pattern of reasoning if there is any such pattern. To see why this is right, note that there are often are several good patterns of reasoning from $\mathrm{R}$ to $\phi$-ing. The fact that the glass contains orange juice is an objective reason to drink on two counts: it would be healthy, and it would be delicious. If I am attracted to treat this fact like an objective reason to drink only as a manifestation of my disposition to drink healthy beverages, I still have an apparent reason to drink if I see that this glass contains orange juice. Accordingly, if my reasoning instantiates only one pattern of competent reasoning, that is enough.

Some might wonder whether there will always be broader patterns of good reasoning to which we can appeal. But I have not assumed that there always will be broader patterns. I have only assumed that when there are broader patterns, the subject must be competent with some of them. Sure, not every good piece of reasoning will be subsumed by some interesting broader pattern. But it would be implausible to deny that there are ever any interesting broader patterns. When there are, competence requires proficiency with some of them. How else can we explain what Weirdo was missing, for example?

\footnotetext{
${ }^{14}$ Here and elsewhere, I use 'reasoning' in a broad sense to mean responding to (possibly bad) reasons.
} 


\subsection{Taking Stock}

With these clarifications in place, I think we should treat CAT* like what it is: a superior theory to the others on offer. Let us briefly take stock of why.

$\mathrm{CAT}^{*}$ avoids overintellectualization without inviting the Problem of Unapparent Reasons. This is achieved by its appeal to the notion of treating something like an objective reason. $\mathrm{CAT}^{*}$ avoids overintellectualization because such treating does not require the possession of any normative concepts. But it still avoids the Problem of Unapparent Reasons, because it is natural to think that if one is attracted to treat $\mathrm{R}$ like an objective reason, $\mathrm{R}$ is an apparent reason and not merely a frictionless apparent fact.

We do not want just any considerations that subjects are attracted to treat like objective reasons to count as apparent normative reasons. Suppose I am attracted to treat P like an objective reason to believe Q via some wildly overgeneralizing incompetence, where I am unaware that I have this incompetence. I do not gain a serious apparent reason to believe Q. CAT*'s appeal to competence addresses this problem for DE RE. Moreover, it does so without appealing to further primitive normative concepts beyond the concept of an objective reason. After all, we analyzed the competences to which CAT* appeals in terms of dispositions to treat objective reasons like objective reasons.

Once again, this does not lead us back to the Problem of Wouldn't-Be Reasons. There is a gap between competence and performance. If one is excusably misled about the favorableness of one's circumstances, one might retain a competence to $\phi$ but not be in a position to reliably $\phi$. This offers a way to diagnose what is happening in the cases that support distinguishing between rationality and correctness. Consider Williams's petrol and tonic case. Bernie does possess an objective reasons-sensitive competence: he is just excusably misled about his circumstances, like the great archer who receives strong misleading evidence that there will not be gusts each time she tries to shoot.

Certainly, the connection between apparent reasons and objective reasons is stronger according to $\mathrm{CAT}^{*}$ than according to theories like DE DICTO. But this is a virtue, not a vice. It is true that rationality does not guarantee actual reliability. But it is not true that the capacities that rational subjects exercise are different from the capacities that many actually reliable subjects exercise. The capacities are the same: what differ are the favorableness of the circumstances and the subject's sensitivity to them. Even if we recognize a notion of rationality that falls between coherence and correctness, we do not need to think that rationality is divorced from correctness: it is a competence to achieve correctness, however fallible and unhelpful in unfortunate circumstances. 


\section{But Don't Envelopes Slice All the Theories?}

CAT* fares better than DE DICTO and DE RE. It does, however, share with both a feature that some find objectionable. Specifically, all three theories entail that apparent reasons are apparently objective reasons. These theories simply understand the 'apparently' in different ways. Call this the Thesis of Apparent Objectivity (TAO).

Some believe there is a decisive reason to reject TAO: namely, that we can rationally do what we know there is not most objective reason to do. This objection to TAO can be illustrated with a case from Jacob Ross:

Three Envelopes. Chester can choose one of three envelopes. He is correctly told by a reliable informant that there is $\$ 800$ in Envelope 1. He is also correctly told there is $\$ 1000$ in either Envelope 2 or 3, and that the envelope that lacks it is empty. But he cannot learn anything else about which might contain it (and knows this). ${ }^{15}$

Cases like Three Envelopes can seem to pose a problem for TAO. Chester ought rationally to pick Envelope 1. But Chester can know that there is more objective reason for him to do otherwise. For he can know that either (i) there is more objective reason to choose Envelope 2 or (ii) that there is more objective reason to choose Envelope 3. After all, there is $\$ 200$ more in one of them. So, Chester ought rationally to make a choice that there is apparently insufficient objective reason to make.

Is that inconsistent with TAO? Many automatically assume that it is. But it is not. We have only discussed theories about what it is for a consideration to be an apparent normative reason to $\phi$. They are not theories about the comparative weight of apparent reasons. Maybe, then, there are ways of weighing apparent reasons that (i) preserve the thought that all apparent reasons are apparently objective (i.e., TAO), but also (ii) affirm that there is sufficient apparent reason for Chester to choose Envelope 1.

Consider:

NO SPECIFIC DOMINANCE (NSD): $\mathrm{R}$ is a sufficient apparent reason to $\phi$ iff

(i) $\mathrm{R}$ is an apparently objective reason to $\phi$,

and

(ii) there is no consideration other than $\mathrm{R}$ that is apparently a stronger objective reason to pursue any specific alternative to $\phi$-ing,

* where specific alternatives include things like taking Envelope 2 but not things like not taking Envelope 1.

\footnotetext{
${ }^{15}$ See Ross (2012).
} 
NSD is compatible with TAO. NSD entails that a sufficient apparent reason must be an apparently objective reason, and hence entails TAO.

NSD is plausible. Suppose that I am $\phi$-ing, and I know that I could never discover a better objective reason to pursue some specific alternative to $\phi$-ing. Suppose moreover that I know that there is a good objective reason to $\phi$. It seems natural for me to conclude that I am rationally permitted to continue to $\phi$. What else am I supposed to do? I cannot rationalize pursuing any specific alternative to $\phi$-ing, because I lack any apparently stronger objective reason to pursue any specific alternative. Moreover, I know that there is at least an objective reason to $\phi$. This is all compatible with my knowing generically that there is something better I could do, if I cannot discover the specific thing that is better.

Similar points apply to Three Envelopes. The fact that there is $\$ 800$ in Envelope 1 is a strong objective reason for Chester to choose it. This fact is apparent to him. Moreover, the generic fact that there is an envelope that contains $\$ 1000$ fails to be an apparent objective reason for Chester to pursue any specific alternative to choosing Envelope 1. Not choosing Envelope 1 is not a specific alternative. There are two ways not to choose, and no apparent objective basis for discriminating. If Chester's apparent reason to choose Envelope 1 is insufficient, there must be an apparent objective basis for discrimination.

This is plausible, and it supports NSD. Isn't withholding from choosing any envelope a specific available alternative? Yes. But there are decisive objective reasons not to withhold: viz., the fact that there is $\$ 800$ within Chester's reach which he will lack if he withholds forever and the fact that he cannot know before acting which of the other two envelopes contains the $\$ 1000$. These are not just apparent facts. They are objective facts. The second fact is a fact only because Chester is ignorant. But it is still an objective fact! ${ }^{16}$

So NSD predicts that Chester has a sufficient apparent reason to choose Envelope 1. This is because Chester's apparent objective reason to choose Envelope 1 is not outweighed by any apparent objective reason for any specific alternative to Envelope 1. This prediction is plausible. And it is compatible with TAO.

Cases like Three Envelopes do not undermine TAO. Since TAO is plausible and CAT* is the best theory on offer that entails it, we can retain our confidence in CAT*.

\footnotetext{
${ }^{16}$ The fact that ignorance has objective effects is often ignored. But it matters: it destroys the tendency to assume that real rather than merely apparent reasons must be ones we would have if we knew all the facts. Dancy (2000: 69) anticipated this point: "Assessing rationality relative to incomplete information does not require us to think that the rationality we are assessing is subjective in any damaging sense.... It is worth remembering in this connection that the fact that I do not know something can itself be a reason. Suppose that my information is limited, and I know this, and that I have no time to make further enquiries. The action I have most reason to do might not be the one that I would have had most reason to do if I had had more time to find out more of what I needed to know. This should remind us of Prichard's example of slowing down at a junction. In that case, the objectivist seemed perfectly able to say that the main reason for slowing down is that one does not know whether any traffic is coming. If one had known that there was no traffic coming, perhaps one would have had no reason to slow down."
} 


\section{Concluding Remarks}

I turn to some loose ends and concluding remarks.

I have argued against two major types of views about apparent reasons and presented an alternative that absorbs their virtues while avoiding their vices. I have also showed that the larger family to which all these theories belong - namely, theories that entail TAO - are not undermined by cases like Three Envelopes.

One might be left wondering whether there are even better theories that fall outside this class. As far as I know, the only other obvious alternative is a dualist one that takes as normatively primitive both objective reasons and apparent reasons (or something in the ballpark). ${ }^{17}$ According to such theories, the best that we can do is point to connections that apparent reasons bear to other "subjectively normative" phenomena like rationality. Since we ought to avoid multiplying normative primitives, my approach is preferable.

Another kind of theory that I have not explicitly considered is a theory on which rationality is to be analyzed in terms of possessed normative reasons. The status of this theory depends upon the status of what Schroeder (2008) calls the Factoring Account. On the Factoring Account, possessing a normative reason is a matter of (i) there objectively existing a normative reason and (ii) one's bearing some possession relation to this preexisting reason. Schroeder rejects this account and takes the idea of a possessed reason as a further normative primitive. This is, of course, just a form of dualism.

But if the Factoring Account is true, the possessed reasons theory does diverge from all the theories discussed so far. Originally I suggested that the 'apparent' in 'apparent reasons' is not a success term: something can be an apparently objective reason in spite of not being an objective reason. But if both the Factoring Account and the possessed reasons theory are true, the 'apparent' is a success term.

This is a vice. Apparent reasons need not be objective reasons or would-be objective reasons. This was the lesson of the Problem of Wouldn't-Be Reasons. Recall again the case of the misled scientists. It appears to the scientists that it is a law that Fs are Gs, but this appearance is misleading. Every time an F appeared to be a $\mathrm{G}$ involved an illusion; in reality, Fs are nomically guaranteed to be non-Gs. The scientists have been correctly told that $\mathrm{X}$ is an $\mathrm{F}$, but nothing more. The fact that $\mathrm{X}$ is an $\mathrm{F}$ is an apparent reason for the scientists to believe that $\mathrm{X}$ is a $\mathrm{G}$. But the fact that $\mathrm{X}$ is an $\mathrm{F}$ is not an objective reason to believe that $\mathrm{X}$ is a $\mathrm{G}$. That fact is an objective reason to believe that $\mathrm{X}$ is not a $\mathrm{G}$.

This is compatible with affirming that there is an objective reason for the scientists to believe that $\mathrm{X}$ is a $\mathrm{G}$. The claim was only that the fact that $X$ is an $F$ is not the objective reason. This is the only claim that needs to be made: it alone shows that there can be apparent reasons that would not be objective reasons if true. ${ }^{18}$ After all, it is true that X

\footnotetext{
${ }^{17}$ See Ross (2006).

${ }^{18}$ Lord (2010) does not address this worry.
} 
is an $\mathrm{F}$ in this case, but this truth is not an objective reason to believe that $\mathrm{X}$ is a $\mathrm{G}$.

Compatibly with all this, one might say that the fact that all Fs have appeared to be $G s$ is itself an objective reason to believe that X is a G. I see no need to resist this claim in worlds where there is an otherwise generally reliable connection between appearance and reality. This doesn't undermine the point, which concerned the status of the fact that $X$ is $F$. Anyhow, we could always imagine skeptical scenarios where appearances are not reliably connected with the facts. In these worlds, there need not be decent objective reasons for beliefs or other attitudes that are perfectly rational.

We might also agree that possessed objective reasons have a role to play other than analyzing rationality. Indeed, I think this is true. I think we ought to distinguish between justification and rationality. Justification also falls short of objective rightness, but it is stronger than rationality: truly justifying reasons must be objective reasons. This leads to a picture on which three reason-involving phenomena must be distinguished:

- Correct $\phi$-ing, which consists in $\phi$-ing in conformity with all objective reasons.

- Justified $\phi$-ing, which consists in $\phi$-ing in compliance with the objective reasons that one possesses.

- Rational $\phi$-ing, which is $\phi$-ing in compliance with all one's apparent reasons.

Assuming that possession can itself be analyzed without appeal to any normative items other than objective reasons, this threefold distinction violates no canons of parsimony.

Possession can be so analyzed. Indeed, I would recommend an account of possession that exploits some of the same concepts used in CAT*. Following Ernest Sosa, we should distinguish between competence and aptness. One $\phi$ s competently when one's $\phi$-ing manifests a competence to succeed, relative to some standard of success. One can succeed and possess competence, but fail to succeed due to one's competence. Apt $\phi$-ing is then $\phi$-ing whose success manifests competence. We have considered attractions to treat considerations like objective reasons, and the competences at issue will be defined just with objective reasons and dispositions. The attractions will be:

- right, when the considerations that attract are in fact objective reasons

- competent, when they manifest dispositions to treat only objective reasons like objective reasons, and

- apt, when their rightness manifests competence (in the earlier senses).

If being competently attracted to treat things like objective reasons is what we need to analyze apparent reasons, being aptly attracted to treat things like objective reasons is what we need to analyze possessed objective reasons. Aptness entails competence, so all possessed normative reasons are objective reasons. This sits well with the Factoring Account. 
This is an extension of the approach that I lack space to further develop here. Apparent reasons were the focus, and there are powerful reasons to doubt that apparent reasons are possessed objective reasons. But it is a virtue of my overall approach that it extends naturally to help us understand possessed objective reasons. Even if one does not accept my view, this is more evidence that my overall approach is worth taking seriously.

\section{References}

Broome, J. 1999. "Normative Requirements." Ratio 12: 398-419.

Broome, J. 2005. "Does Rationality Give Us Reasons?" Philosophical Issues 15: 321-337.

Broome, J. 2007. "Does Rationality Consist in Correctly Responding to Reasons?" Journal of Moral Philosophy 4: 349-374.

Broome, J. 2013. Rationality through Reasoning. Oxford: Blackwell.

Chisholm, R. M. 1957. Perceiving: A Philosophical Study. Ithaca: Cornell University Press.

Clark, M. 1963. "Knowledge and Grounds." Analysis 24: 46-48.

Dancy, J. 2000. Practical Reality. Oxford: Oxford University Press.

Dancy, J. 2004. Ethics without Principles. Oxford: Oxford University Press.

Fodor, J. 1998. Concepts: Where Cognitive Science Went Wrong. Oxford: OUP.

Harman, G. 1973. Thought. Princeton: Princeton University Press.

Kolodny, N. 2005. "Why Be Rational?" Mind 114: 509-560.

Lord, E. 2010. "Having Reasons and the Factoring Account." Phil. Studies 149: 283-296.

Parfit, D. 2001. "Rationality and Reasons" in Dan Egonsson, Bjorn Petterson and Toni RonnowRasmussen (eds.) Exploring Practical Philosophy. Aldershot: Ashgate.

Parfit, D. 2011. On What Matters. Oxford: Oxford University Press.

Ross, J. 2006. Acceptance and Practical Reason. Ph.D. Thesis, Rutgers University.

Ross, J. 2012. "Rationality, Normativity, and Commitment" in Oxford Studies in Metaethics 7. Oxford: Oxford University Press.

Scanlon, T. M. 1998. What We Owe to Each Other. Cambridge MA: Harvard University Press.

Schroeder, M. 2007. Slaves of the Passions. Oxford: Oxford University Press.

Schroeder, M. 2008. "Having Reasons." Philosophical Studies 139: 57-71.

Schroeder, M. 2009. "Means-End Coherence, Stringency, and Subjective Reasons." Philosophical Studies 143: 223-248.

Schroeder, M. 2011. "What Is It To 'Have' A Reason?" in Reisner, A. and Steglich-Petersen, A. (eds.) Reasons for Belief. Cambridge: Cambridge University Press.

Schroeder, M. Ms. "The Negative Existential Reason Fallacy." Unpublished MS, USC.

Sosa, E. 1991. Knowledge in Perspective. Cambridge: Cambridge University Press.

Sosa, E. 1993. "Proper Functionalism and Virtue Epistemology." Nous 27: 51-65.

Sosa, E. 2011. "How Competence Matters in Epistemology." Phil. Perspectives 24: 465-475.

Way, Jonathan. 2009. "Two Accounts of the Normativity of Rationality." JESP 4.2: 1-8.

Wedgwood, Ralph. 2003. "Choosing Rationally and Choosing Correctly" in Stroud, S. and Tappolet, C. Weakness of Will and Practical Irrationality. Oxford: Oxford University Press.

Williams, B. 1981. Moral Luck. Cambridge: Cambridge University Press. 